\title{
Zorica Krželj-Čolović
}

University of Dubrovnik

Department of Economics and Business Economics, Croatia

E-mail: zkrzelj@unidu.hr

\section{REGIONAL COMPETITIVENESS}

JEL classification: R11

\begin{abstract}
Individual city and regional authorities in many countries have themselves taken up the issue of "competitiveness" as part of their own economic development agendas: competitiveness has come to be regarded as critical for understanding and promoting local economic performance. Like their national counterparts, regional and city policy-makers have become preoccupied with knowing the relative competitive standing of their local economies compared with others, not just other regions and cities within their own national jurisdiction, but with areas elsewhere across the globe. Devising local strategies to improve the competitiveness of their locality is now regarded as a primary task by many regional and city policy-makers.
\end{abstract}

Key words: competitiveness, clusters, comparative advantage 


\section{INTRODUCTION}

Three sets of influences might be identified as explaining why the idea of regional competitiveness has recently assumed such importance in policy circles.

The first has to do with the general discourse around globalisation. The argument, propounded by goverments, policy-makers, and academics of all political and ideological persuasions, is that globalisation brings with it not only expanding trade but also increasingly intense competition between enterprises, between nations, and between regions and cities over shares of new and existing markets. The economies like Brazil, Russia, India and China are typically portrayed as seriously challenging theeconomies of the old advanced nations, not only in traditional export markets but also as prospective competitors in an increasing array of high-value and high-technology activities. No nations, no region, no city, it is argued, is immune from the implicationsof the new global competition.

A second factor has been growth ofregions and cities themselves as arenas of economic policy intervention and economic governance. The policy emphasis on the supply-side over the past two decades or so has led states to argue that many economic supply-side frictions, inflexibilities, and barriers to national growth originate at the local level and are therefore best addressed at that scale. There has been a demand, therefore, for expert knowledge on how to measure and promote local competitiveness. One inevitable trend this has spawned is the compilation of regional competitiveness indexes, league tables, and the desire for benchmarking.

Third, if the rise of regional competitiveness talk in policy circles has been bound up with the discourse around globalisation, it has been equally influenced by the writings of key academics. Despite the fact that there has been, and continues to be, academic debate about what, precisely, is meant by the notion of regional competitiveness within policy circles, if there is a dominant view on this concept it is Porter's cluster model, and the particular interpretation and explanation of local and regional competitiveness he uses that model to promote. Over the past two decades, Porter more than anyone else has championed a whole new policy and consultancy industry concerned with measuring and promoting competition advantage.

Porter's notion of the cluster is central to his view about the nature and drivers of competitiveness. In fact, the two concept are inextricably interlinked in his work and policy advice: it is the geographical clustering of related enterprises that creates various localised external increasing-returns effects that in turn improve the competitiveness of the enterprises concerned compared to their non-clustered counterparts. Clustering is thus claimed to be a key source of competitive advantage both for the enterprises involved and for the region where the cluster is located: cluster and their promotion are key to regional competitiveness. 


\section{THE IMPACT OF CLUSTERING ON COMPETITIVE PERFORMANCE OF ENTERPRISES}

The underlying assumption of Porter's cluster model is that clustering enhances innovation, innovation enhances productivity, and higher productivity improves enterprise performance.

Cluster studies have tended to focus on case studies of innovative regional clusters, typically, highly successful ones. While such studies sometimes compare the performance of one such cluster with another, such as Silicon Valley and Route 128 (Saxenian, 1994, p. 67), they rarely compare enterprises in these clusters with similar unclustered enterprises, nor whether significant variations in competitive performance exist across enterprises within the same cluster. Further, the relevance of anecdotal evidence from these specific, typically self-contained, and rather distinctive clusters for a general discussion on the importance of local and regional conditions for the competitiveness of enterprises can be questioned (Lundquist and Olander, 1999, p. 148). Martin and Sunley (2003, p. 21) observed that the evidence for the beneficial effects of clustering on enterprise performance was patchy, mixed, and inconsistent. Despite the increasing diffusion of cluster ideas and the proliferation of cluster strategies, the growing research into clusters and enterprise performance has confirmed rather than undermined this observation. Research has produced a variable and mixed set of findings about whether innovation, productivity, and growth tend to be higher within, as against outside, clusters. While a number of cases of particular clusters have tended to be broadly supportive of the effects envisaged by Porter, more extensive comparative work has found little strong support for the claim that clustering demonstrably raises enterprise performance.

The importance cause of the absence of a clear universal relationship between clusters, enterprise performance, and innovation is that the consequences of clusters are not static but alter as the clusters and their constituent enterprises, industries, and institutions evolve. İt is now widely recognized that while clustering may reinforce growth in the early stages of an industry, it can conversely lead to and reinforce decline during the mature and later stages of an industry's development, due to congestion and competition effects (Braunerhjlem and Carlsson, 1999, p. 284). Rocha's (2004, p. 391) comprehensive review of the relations between clustering and entrepreneurship cautiously concludes that it is difficult to generalise: "In effect, both positive results and caveats are found at different levels of analysis and at different stages of development of a cluster". The existing literature includes several examples where clustering produces beneficial effects, especially for young enterprises and new entrants in knowledge-intensive industries and producer services (Wennberg and Lindqvist, 2010, p. 232). Gilbert et al. (2008, p. 411) find that clustering boosts the innovation performance of weaker young enterprises.

Ultimately, of course, the source of a enterprise's competitive advantage lies in its dynamic capabilities or organisational processes that create, integrate, recombine, and release (Eisenhardt and Martin, 2000; Ambrosini and Bowman, 2009). Without such capabilities, enterprises are likely to enjoy only a short-term 
competitive advantage and will fail to respond to their constantly changing environments. Such capabilities are typically shaped both by internal processes, such as path-dependent learning, management practice, cognition, and strategy, and by external factors, such as business environemnt and the degree of uncertainty (Ambrosini and Bowman, 2009, p. 33). Clusters are, in effect, one dimension of this external environment which may shape and moderate dynamic capabilities.

While these caveats undoubtedly have some force, the basic point remains, namely, that there is much empirical evidence to question the claim that clustering enhances the competitiveness of enterprises, and hence regions, as there is evidence to support it. Clearly, enterprises co-locate because certain benefits are perceived from doing so, and the local clustering of similar and related enterprises may well facilitate labor hiring, access to specialist supporting enterprises, and perhaps even certain types of knowledge spillover and technological learning. But clustering by itself does not guarantee that such processes will necessarily occur, or, even if they do, that they will necessarily have the alleged beneficial impacts on enterprise performance. As research has made clear, much will depend on the type of industry, the capabilities of the enterprises involved, historical circumstances, the stage of development of the cluster, and a host of other contextual and conjunctural factors. İ short, the evidence is mixed, and caution should therefore be exercised when invoking the cluster model to explain or define regional competitiveness. Further, the cluster model perhaps assigns too much importance to the local business context, to local interactions and externalities.

\section{THE COMPETITIVENESS OF REGIONS: CLUSTERS OR COMPARATIVE ADVANTAGE?}

A region's enterprises may be highly productive, and may enjoy a competitive advantage in their respective industries and markets even though they do not exhibit clustering. On the other hand, a region may have several clusters, but these need not (or need no longer) be competitive, so that the regional economy may suffer from an inferior growth rate or standard of living. In such cases, the cluster model would seem an incomplete conceptualisation of regional competitiveness. Another, and more general, way of conceptualising regional competitiveness is provided by the concept of comparative advantage that originally derives from international trade. Trade is a key aspect when measuring competitiveness.

Porter (1990, p. 12) emphasizes that it is export-orientated clusters that play a particularly important role in determining the competitiveness of locations and regions. He argues that it is not the particular sectors in which a location or region specialises that matter: it is not what a region produces, but how well it produces it, which is where clustering is assumed to play a highly positive role since, the argument goes, clustering improves the efficiency with which a region produces its goods and services. 
What it appears to have then is, on the one hand, a comparative advantage theory of regional competitiveness which draws on Ricardian-type factor endowments, and on the other, Porter's cluster theory which has strong links to Smithian and Marshallian - type increasing returns. But does Porter's "alternative" cluster theory actually run counter to notions of comparative advantage? Is it really that different? Much depends on how comparative advantage is interpreted and conceptualised in a regional context. Porter's portrayal of comparative advantage theory is the traditional, static "fixed factor endowments" view; and that is not difficult to criticise. But comparative advantage theory has in fact moved on from the standard Ricardian model that Porter attacks (Maneschi, 2000; Redding, 1999; Krugman, 2009).

The increasing-returns effects arising from industrial localisation within a nation give that nation a comparative advantage in the industry concerned. As an extension of this thinking to a regional context, Krugman has placed considerable emphasis on these externalities as a driver of what he now acknowledges as regional competitiveness: "An industry or cluster of industries generates spillovers, which reinforces that industry's local advantage, or in some cases spillovers to other industries, which are thereby encouraged to locate in a particular region" (Krugman, 2005, p. 39). Clearly, clusters are one form that such industrial localisation may take.

The basic point is that if a wider view is taken of endowments or resources, and learning, technology, and a region's externalities and fundamentals are included in those resources, the idea of comparative advantage takes on renewed relevance in discussion of regional competitiveness. Furthermore, it becomes a dynamic concept. In his cluster theory Porter puts great store on innovation and upgrading as key to maintaining the competitiveness of enterprises, of clusters, and thus of regions, over time. A dynamic, resource-based notion of comparative advantage has a similar emphasis. What is essential to dynamic regional comparative advantage is adaptation to constantly changing markets, competition, and technology. How well enterprises adapt to the ever-shifting threats and opportunities that arise in the global economy determines whether they remain competitive in their respective industries. In terms of a regional economy as a whole, adaptation takes on a further dimension, not only in relation to the ability of its enterprises, clusters, and industries to adapt to changing market conditions and opportunities, so as to maintain their competitiveness, but also in relation to how well the economy is able to develop new productive industries, sectors, and technologies of activity over time; that is, how well it adapts its economic structure. Comparative advantage is an evolving feature of a regional economy, and adaptation is the key to its maintenance over the long term.

What all of this suggests is more general conception of regional competitiveness than that provided by the cluster model - possibly of the sort illustrated in Figure 1. 


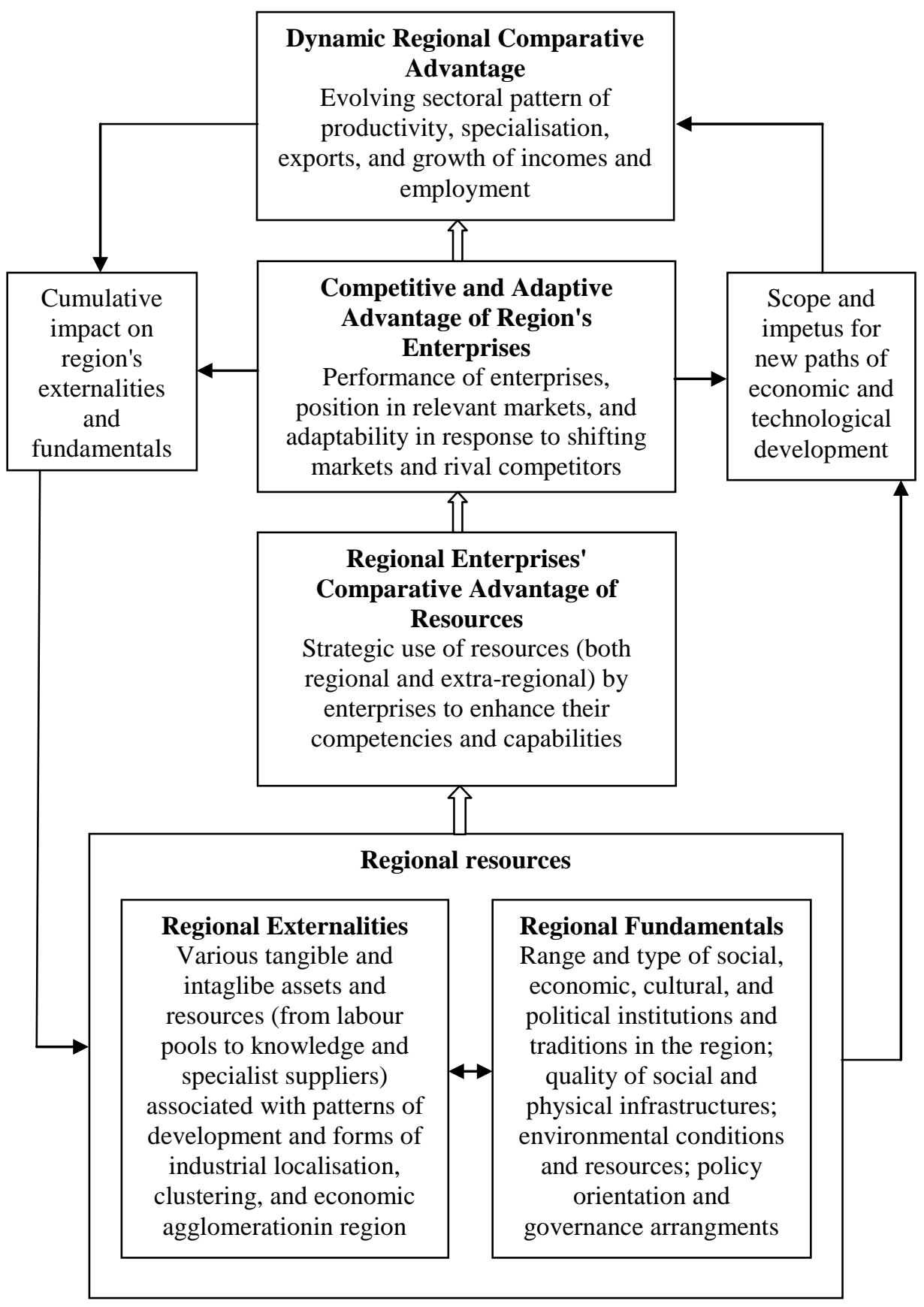

Figure 1. Model of regional competitiveness 
A region's resources afford location-specific comparative advantage (or disadvantage) to a region's enterprises. How enterprises drawn on and deploy these resources, in combination with their own internal resources, influences their competencies and capabilities, and thence their productivity, innovation, and competitive advantage in the markets and export sectors for which they produce and in which they compete. Since market conditions are constantly evolving, the competitive advantage of a region's enterprises will also depend on how well they adapt to these shifting conditions.

At the regional scale, the outcome will be a particular pattern of interenterprise and inter-sectoral competitive advantage that represents the comparative advantage of the region relative to other regions. This particular pattern is not static, however, but evolves over time as the competitive advantage and adaptability of its enterprises change. Further, the region's resources and the changing competitive fortunes of the region's enterprises together influence the scope and impetus for the emergence of new paths of industrial and technological development which may form the basis of new forms of regional comparative advantage. At the same time, the region-wide pattern of economic development, specialisation, and comparative advantage can be expected to feed back on the region's resources (both externalities and fundamentals): either to reinforce existing resources, characteristics, and assets, or to reshape them. Regional competitiveness, then, is a dynamic, co-evolutionary process, involving both elements of continuity (and path dependence) and elements of change and adaption.

The model in Figure 1. does not depend on the presence of clusters, as other forms of economic agglomeration and spatial organisation can also give rise to favorable externalities on which a region's enterprises can drawn. And a region's fundamentals may be more important than its externalities for the competitiveness of local enterprises. But neither does this conception rule out clusters nor deny that they may play a key role clusters play in shaping the competitiveness of a region's enterprises is a matter for empirical enquiry, not theoretical presumption.

\section{CONCLUSION AND IMPLICATIONS}

The comparative advantage theory is dynamic, not static. It recognises that enterprises are constantly having to upgrade and reconfigure their competitive advantage in the face of changing market and competitive conditions. How this is achieved, and the extent to which is accomplished, will vary from enterprise to enterprise, even in the same industry, and is shaped by the external resources available to enterprises in the region in which they are located: geography matters. To our way of thinking, the idea of regional dynamic comparative advantage is more general than Porter's cluster model, and subsumes the latter. 
It is inevitable that cluster initiatives will suport some industries and not others (Hospers et al., 2009, p. 291). Porter and his associates have strongly denied this and argued that cluster policies should support all clusters: "In cluster theory, all clusters can improve productivity and deserve attention” (Porter 1998, p.12). Porter insists that policy should not seek to build and construct clusters in a top-down fashion. Ketels adds that the selection of clusters should be pragmatic and respond to those clusters that want to engage with public authorities. But in the absence of clear definitions of when a spatial collection of enterprises has sufficient critical mass, proximity, and interrelatedness to represent a cluster, the exhortation to support those clusters that are seeking policy help seems to be an inconclusive and risky policy recommendation.

The importance of comparative advantage means that any decision to support a cluster must take into account several key issues, including whether the cluster is based on the use of resources that the region in question can provide efficiently, whether the cluster can adapt and compensate by exploiting other resources, and how the development of the cluster will alter those resources through feedback effects.

İn our view, clusters are the best only one element of policies intended to promote and enhance regional competitiveness. Aswe have noted, the implication of the interpretation of regional competitiveness we have adopted here is that any targeted measures designed foster clusters should be set in the context of measures designed to strengthen regional externalities and fundamentals. There are many forms of external dynamic advantage that do not depend on the presence of clusters, and there are no grounds for attaching lower priority to these. Equally, regional fundamentals have a critical role in shaping economic development. What this means is that cluster initiatives by themselves are unlikely to provide a comprehensive means of improving the institutional and organisational contexts for regional competitiveness. The importance of regional fundamentals and externalities in dynamic comparative advantage means that regional policy has to seek more comprehensive and holistic measures that shape the business and knowledge environment for the whole regional economy and not just for those enterprises recognised as being located in clusters. And above all, given the regional competitiveness is a dynamic process, not a statistic state of affairs, the regional policy task is essentially about promoting, enhancing, and fostering adaptation.

\section{REFERENCES}

Ambrosini, V., Bowman, C. (2009). What are dynamic capabilities and are they a useful construct in strategic management?. International Journal of Management Reviews, 11 (1), pp. 29-49.

Braunerhjelm, P., Carlsson, B. (1999). Industry clusters in Ohio and Sweden, 1975-1995. Small Business Economics, 12(4), pp. 279-293. 
Eisenhardt, K.M., Martin, J. (2000). Dynamic capabilities: What are they?. Strategic Management Journal, 21(10/11), pp. 1105-1121.

Gilbert, B.A., McDougall, P.P., Audretsch, D.B. (2008). Clusters, knowledge spillovers and new venture performance: An empirical examination. Journal of Business Venturing, 23(4), pp. 405-422.

Hospers, G.J., Desrochers, P., Sautet, F. (2009). The next Silicon Vallley? On the relationship between geographical clustering and public policy. International Entrepreneurship Management Journal, 5(3), pp. 285-299.

Krugman, P. (2005). Second winds for industrial regions?. In Coyle, D. et al. (eds.) New Wealth for Old Regions: Scotland's Economic Prospects. Princeton NJ: Princeton University Press, pp. 35-47.

Krugman, P. (2009). The increasing returns revolution in trade and geography. American Economic Review, 99(3), pp. 561-571.

Lundquist, K.J., Olander, L.O. (1999). Firms, regions and competitiveness: A broadbrush approach. Geografiska Annaler: Series B, Human Geography, 81(3), pp.145-164.

Maneschi, A. (2000). How new is the "new trade theory" of the past two decades?. Working paper 00-W27, Department of Economics, Vanderbilt University, Nashville.

Martin, R., Sunley, P. (2003). Deconstructing clusters: Chaotic concept or policy panacea?. Journal of Economic Geography, 3(1), pp. 5-35.

Porter, M.E. (1990). The competitive advantage of nations. Harvard Business Review, 68(2), pp. 73-93.

Porter, M.E. (1998). The Adam Smith address: Location, clusters and the "new" microeconomics of competition. Business Economics, 33(1), pp. 7-13.

Redding, S. (1999). Dynamic comparative advantage and the welfare effects of trade. Oxford Economic Papers, 51(1), pp. 15-39.

Rocha, H.O. (2004). Entrepreneurship and development: The role of clusters. Small Business Economics, 23(5), pp. 363-400.

Saxenian, A. (1994). Regional Advantage: Culture and Competition in Silicon Valley and Route 128. Cambridge: Harvard University Press.

Wennberg, K., Lindqvist, G. (2010). The effect of clusters on the survival and performance of new firms. Small Business Economics, 34(3), pp. 221-241. 